\title{
MECHANISMS FOR ENSURING THE ECONOMIC SECURITY OF DEPRESSED REGIONS
}

\author{
Matvey S. Oborin \\ Perm Institute (Branch) of Russian Economic University named after G.V. Plekhanov, Perm, Russian Federation; \\ Perm State National Research University, Perm, Russian Federation; \\ Perm State Agro-Technological University named after Academician D.N. Pryanishnikov, Perm, Russian Federation
}

\begin{abstract}
The strategic policy of the Russian Federation is structured in such a way that the priority task is to preserve and support economic security, create optimal conditions for the development of socio-economic cooperation and sustainable sectoral development in accordance with the norms of the federal state. Regional economic systems are characterized by a unique combination of economic, social, informational, environmental and other mandatory components; the presence of many different connections; circulation of large flows of financial, material and informational resources, representing in their entirety the socio-economic potential of the region. In order to make better use of all these resources, each region separately must operate on the principles that determine stability and security. The article considers the implementation of targeted programs in depressed regions as one of the ways to reduce the lag in the level of socio-economic development. The article analyzes the experience of implementing federal programs in the Republic of Dagestan as a depressed region of Russia, as well as the tasks that were solved with the help of these regional policy instruments. The author's view on the strengths and weaknesses of the implementation of a number of federal targeted programs in the region is presented. The aim of the work is to find new forms of interaction between government, business and society for the transition of depressed regions to a new economic level.
\end{abstract}

Key words: economic security, depressed region, investment, industry, development strategy, government regulation, economic crisis, production decline.

Citation. Oborin M.S. Mechanisms for Ensuring the Economic Security of Depressed Regions. Vestnik Volgogradskogo gosudarstvennogo universiteta. Ekonomika [Journal of Volgograd State University. Economics], 2021, vol. 23, no. 2, pp. 29-41. (in Russian). DOI: https://doi.org/10.15688/ek.jvolsu.2021.2.3

\section{МЕХАНИЗМЫ ОБЕСПЕЧЕНИЯ ЭКОНОМИЧЕСКОЙ БЕЗОПАСНОСТИ ДЕПРЕССИВНЫХ РЕГИОНОВ}

\author{
Матвей Сергеевич Оборин \\ Пермский институт (филиал) Российского экономического университета им. Г.В. Плеханова, \\ г. Пермь, Российская Федерация; \\ Пермский государственный национальный исследовательский университет, г. Пермь, Российская Федерация; \\ Пермский государственный аграрно-технологический университет им. акад. Д.Н. Прянишникова, \\ г. Пермь, Российская Федерация
}

Аннотация. Стратегическая политика Российской Федерации построена таким образом, что приоритетной задачей является сохранение и поддержка экономической безопасности, создание оптимальных условий для развития социально-экономического сотрудничества и устойчивого отраслевого развития в соответствии с нормами федеративного государства. Региональным экономическим системам присуще уникальное сочетание экономической, социальной, информационной, экологической и других обязательных компонент; наличие 
множества разнообразных связей; циркуляция больших потоков финансовых, материальных и информационных ресурсов, представляющих в своей совокупности социально-экономический потенциал региона. Для того чтобы более результативно использовать все перечисленные ресурсы, каждый регион в отдельности должен функционировать на принципах, обусловливающих стабильность и безопасность. В статье рассматривается реализация целевых программ в депрессивных регионах как один из способов сокращения отставания в уровне социально-экономического развития. Анализируются опыт реализации федеральных программ в Республике Дагестан как депрессивном регионе России, задачи, которые решались с помощью указанных инструментов региональной политики. Излагается авторский взгляд на сильные и слабые стороны реализации ряда федеральных целевых программ в регионе. Цель работы заключается в поиске новых форм взаимодействия власти, бизнеса и общества для перехода депрессивных регионов на новый экономический уровень.

Ключевые слова: экономическая безопасность, депрессивный регион, инвестиции, промышленность, стратегия развития, государственное регулирование, экономический кризис, спад производства.

Цитирование. Оборин М. С. Механизмы обеспечения экономической безопасности депрессивных регионов // Вестник Волгоградского государственного университета. Экономика. - 2021. - Т. 23, № 2. - С. 29-41. DOI: https://doi.org/10.15688/ek.jvolsu.2021.2.3

\section{Введение}

В России стратегия социально-экономического развития связана с территориальным потенциалом, значительным количеством природных и человеческих ресурсов. Диспропорции финансово-экономических и социальных показателей в регионах существенно осложняют достижение приоритетных целей, замедляют темпы инновационного роста и повышения конкурентоспособности экономики государства. Ограничением устойчивого развития субъектов страны являются территории со сложным социально-экономическим состоянием, которые входят в категорию депрессивных.

Экономической депрессией является системный кризис, связанный с упадком и деградацией промышленности, неспособностью к самостоятельному воспроизводственному процессу. В научной литературе определены признаки депрессивности региона:

- политические и военные угрозы, границы с территориями боевых действий;

- монопрофильность основных экономических субъектов, продукция которых не пользуется спросом;

- производство, связанное с обслуживанием и комплектацией предприятий, связи с которыми разрушились в период реформ и трансформации политического и экономического уклада;

- высокая доля населения предпенсионного возраста, отток трудоспособных кадров и молодежи в более развитые районные центры;
- низкий уровень развития бизнес-среды и услуг, социально значимых для населения, влияющих на качество жизни;

- высокая безработица, сопровождающаяся одновременно дефицитом цифровых высокотехнологичных кадров;

- низкий уровень доходов;

- инвестиционная непривлекательность территории.

В России депрессивные регионы могут обладать высоким потенциалом развития промышленности, сельского хозяйства, экологически чистых производств, которые вследствие трансформации макроэкономических процессов оказались на периферии распределения товарно-материальных и финансовых потоков. Состояние социально-экономической депрессии субъектов страны негативно влияет не только на общие темпы развития, но и обеспечение безопасности.

Анализ научных работ, посвященных проблемам управления и обеспечения экономической безопасности депрессивных регионов позволяет сделать ряд выводов [Курляндская и др., 2016]:

1) экономическая система депрессивных регионов должна комплексно регулироваться разнообразными инструментами и методами, имеющими проектноориентированную основу, только в том случае можно предполагать положительный эффект;

2) необходимо сочетание направлений: отраслевые программы, кадровая политика, инвестиционные программы, которые могут 
существенно преобразовать отраслевые предприятия, модернизировать и диверсифицировать производство на основе цифровых технологий;

3) управление должно осуществляться с учетом потребностей территории, целей и задач федерального, регионального и муниципального уровней, поскольку каждый уровень управления ориентирован на оперативные задачи и опыт решения проблем - от макроэкономических до локальных;

4) основой стратегии должен быть принцип интеграции территорий и ее производственных бизнес-единиц в более развитые сетевые структуры, что позволит более эффективно развиваться.

Опыт России в территориально-пространственной организации производства основывался и на специализации разветвленной структуры производства, охватывающей ключевые функциональные направления по кластерному или сетевому типу. Ограниченность систем управления подобных структур и трансформация экономических связей привели к неспособности адаптироваться к новым условиям производственно-финансовой и рыночной деятельности. Сложный период экономических реформ и производственный коллапс, обусловленный изменением роли государства в регулировании экономических отношений, способствовали сокращению объемов производимых товаров и продукции, прекращению торгово-экономических связей, разрыву производственных циклов вследствие территориальной удаленности взаимосвязанных хозяйствующих субъектов.

Немаловажным стал финансово-инвестиционный фактор и перераспределение потоков денежных средств. Невозможность участвовать в крупных сетевых объединениях и получать ликвидные ресурсы повлияла на снижение эффективности крупных компаний. Местные производители были вынуждены сокращать объемы производства в целях оптимизации и сокращения убытков, реализовывать продукцию непосредственно населению.

Данные факторы оказали решающее влияние на деградацию отраслевых предприятий и их изоляцию, а затем и банкротство, что в территориальном масштабе привело к депрессии отдельных территорий [Плотников и др., 2013].
В настоящее время территориально-отраслевое управление базируется на нескольких подходах, среди которых преобладает проектно-целевой, позволяющий комплексно подходить к решению проблем и ограничений на основе системного целеполагания, формирования этапов и показателей. Сложность реализации данного подхода связана с многокритериальностью индикаторов описания экономической системы, которые могут быть классифицированы по различным основаниям (см. рис. 1).

Рационально спланированные показатели, механизмы и инструменты их достижения будут способствовать поэтапному восстановлению экономики депрессивных территорий и повышению экономической безопасности региона в целом.

\section{Результаты исследования}

Неоднородность экономического пространства России обусловлена природно-климатическими и социально-экономическими различиями, что создает макроэкономические риски. Различия по ключевым показателям между субъектами страны остаются значительными, несмотря на то что в последние годы динамика диспропорции существенно замедлилась благодаря централизованным мерам бюджетной поддержки, основной целью которой является достижение приемлемого уровня экономической безопасности.

Экономическая безопасность региона является стабилизирующим фактором национальной и экономической безопасности страны, способствует сохранению высоких темпов научно-технического, инновационного и конкурентного развития экономики, ее адаптации к макроэкономическим и геополитическим шокам [Ногмова и др., 2016].

Концептуальные основы экономической безопасности недостаточно проработаны на теоретическом и методическом уровнях, основное определение данного понятия: устойчивость развития экономических процессов и качества жизни населения при сохранении достаточного потенциала конкурентоспособности и относительной автономности воспроизводства, которые поддерживаются нормативно-правовой, институциональной средой. 
Формирование оценочных критериев и параметров экономической безопасности регионов и территорий страны должно ориентироваться на ситуационную устойчивость внутренних экономических процессов вне относительной зависимости от глобальных факторов. Данный подход предполагает, что внешне риски не окажут шокового влияния на экономику регионов и территорий, поскольку существующие механизмы, резервы и возможности системы управления позволяют осуществлять как оперативное, так и превентивное реагирование на негативные явления.

Сложившиеся научно-теоретические подходы к управлению регионом, в том числе и с точки зрения экономической безопасности, рассматривают его как целостный объект с определенной структурой и сложными взаимосвязями. Процесс развития потенциала экономической самостоятельности и безопасности должен ориентироваться на потребности общества, бизнес-среды и органов власти, учитывать интеграционные тенденции, что будет способствовать достижению запланированных эффектов [Ендовицкий и др., 2014].

Стратегия обеспечения экономической безопасности регионов страны связана с фор- мированием эффективной системы управления и устранением диспропорций территориально-отраслевого развития. Интегрированная социально-экономическая и рыночная среда позволяет получать дополнительные преимущества от сотрудничества и кооперации с более развитыми субъектами. Необходимые условия для формирования межтерриториальных и межотраслевых взаимосвязей должны обеспечивать органы власти.

Включение в более развитые бизнесструктуры создает устойчивый социальноэкономический каркас региона, способствует распределению и минимизации рисков, поэтому создание благоприятных условий на региональном и территориальном уровне отвечает интересам государства, глобальным целям и задачам. Однако даже в одном регионе социально-экономическое развитие осуществляется неравномерно, выделяются зоны с высокими темпами производства и уровнем жизни, депрессивные территории с перечисленными выше проблемами и ограничениями. На федеральном уровне финансовые ресурсы перераспределяются между бюджетами субъектов в форме субсидий, дотаций и иных форм прямого целевого фи-

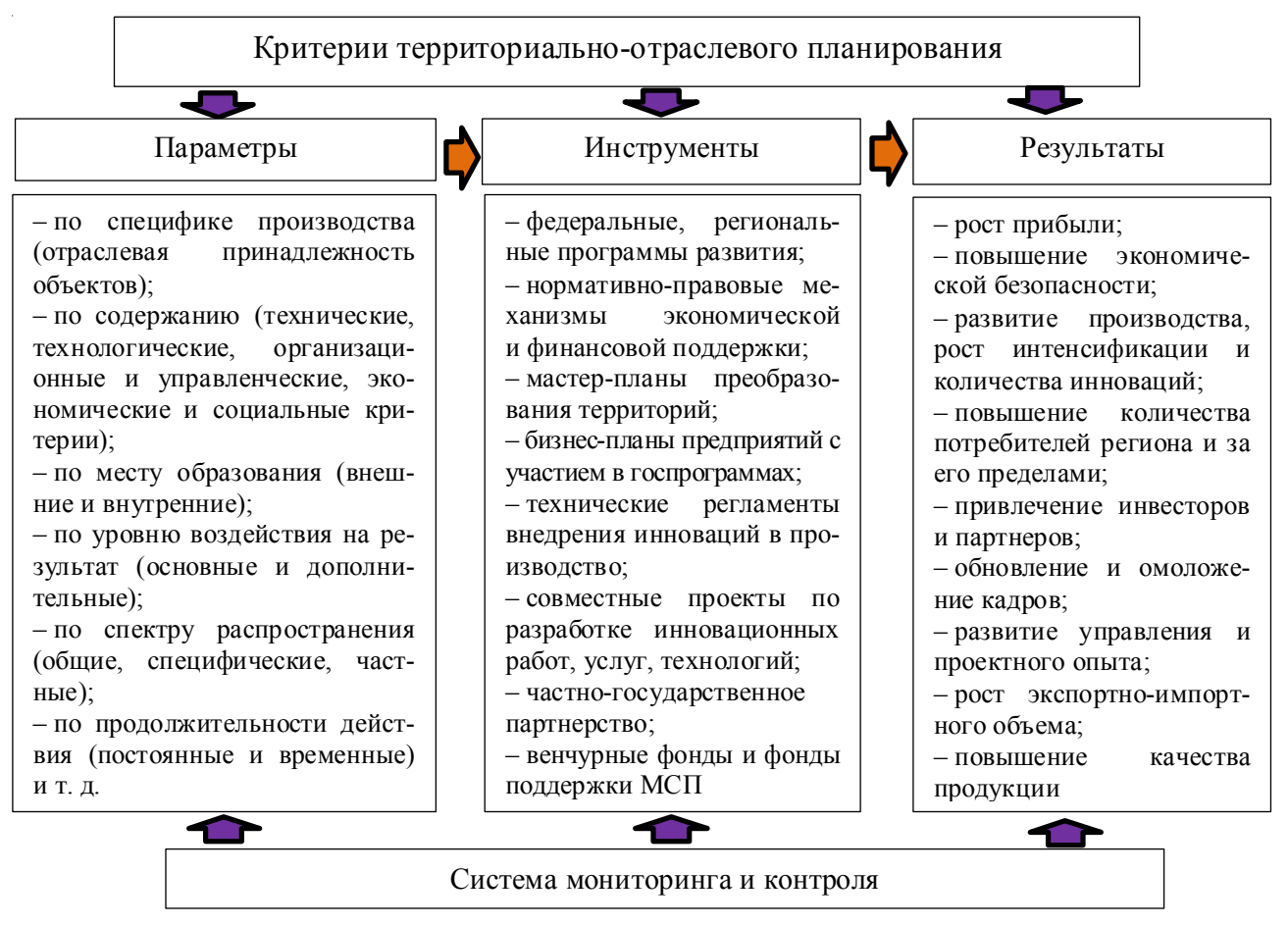

Рис. 1. Критерии и результаты территориально-отраслевого планирования

Примечание. Составлено автором. 
нансирования в целях преодоления существенных диспропорций.

Анализ научных работ выявил различные критерии классификации регионов в зависимости от уровня социально-экономического развития. Единство мнений можно отметить в том, что территориальное неравенство проявляется в структурных показателях доходной и расходной частей бюджета, качестве жизни населения, а также сложившейся и потенциальной специализации, которая определяет направления развития производства и сферы услуг, условия решения социальных проблем и ограничений.

Вместе с тем в научной литературе не сформированы классификационные модели, направленные на оценку экономической безопасности регионов в зависимости от уровня социально-экономического развития. Целесообразным признан многокритериальный подход, охватывающий стандартные экономические показатели, территориальные характеристики, инновационно-технологические и институциональные параметры, благосостояние населения и качество его жизни. Формирование модели, характеризующей уровень экономической безопасности, имеет практическое значение, поскольку определяет степень регулирования государством территориального развития, инструментальную платформу достижения целевых показателей, а также объемы финансово-инвестиционной поддержки.

Классификации регионов по уровню экономической безопасности также предпринимались в научной литературе неоднократно, при этом ключевые параметры могут существенно варьироваться:

- целеполагание территориального развития и качество жизни населения, проживающего на данной территории;

- экономический рост, преступность, благосостояние населения [Долганова и др., 2017];

- предельные показатели состояния экономики, позволяющие ситуационно определить лидирующие и отстающие экономические системы, выделить нормальный, докризисный и кризисный уровни экономической безопасности;

- показатели экономического роста, рынка труда и социального развития, на основе которых формируется низкий, средний и высокий уровень экономической безопасности [Акьюлов, 2015];

- параметры благосостояния населения [Хадисов, 2015].

Процессный подход к определению уровня экономической безопасности регионов представлен в таблице 1.

Анализ научных работ свидетельствует о том, что причины многих угроз экономической безопасности связаны с региональными проблемами и ограничениями, которые существенно замедляют общие темпы социальноэкономического развития субъектов РФ. В представленном процессном подходе выбор классификационных критериев и параметров территориально-отраслевого планирования должен основываться не только на показателях статистики, но и внутренних причинных связях. Экспертная оценка должна включать также анализ:

- цикличность основных производственных процессов в отраслях, формирующих ВРП, либо потенциально значимых для будущей специализации региона;

- направления и пределы зависимости региона от внешних поставок товаров первой необходимости для населения и бизнессреды;

- параметры социального обслуживания и жизнеобеспечения населения.

Опыт реализации целевых проектов в регионах со сложной социально-экономической ситуацией свидетельствует о том, что преобладают внутренние угрозы, которые оказывают ключевое влияние на неспособность экономики к воспроизводству (см. табл. 2).

Система государственных мер поддержки должна быть направлена на формирование и сохранение устойчивости социально-экономических взаимосвязей, иначе расходование бюджетных средств будет неэффективным и краткосрочным. Стабильность связана с надежностью и постоянством вертикально-горизонтальной кооперации внутри экономической системы региона, которая может распространяться за его пределы. С учетом названных внутренних угроз меры по обеспечению экономической безопасности депрессивных регионов представлены в таблице 3 . 
Процессный подход к определению уровня экономической безопасности регионов

\begin{tabular}{|c|c|c|}
\hline Ключевые цели & Описание процедуры & Методологические подходы \\
\hline \multicolumn{3}{|c|}{ 1. Определение групп показателей для оценки уровня экономической безопасности } \\
\hline $\begin{array}{c}\text { Разработка направлений классифи- } \\
\text { кации показателей, определяющих } \\
\text { экономическую безопасность } \\
\text { региона }\end{array}$ & $\begin{array}{c}\text { Формирование критериев } \\
\text { и групп для анализа } \\
\text { и ситуационной оценки }\end{array}$ & $\begin{array}{c}\text { Социологические методы, интервью, } \\
\text { экспертная оценка, } \\
\text { эконометрическое моделирование }\end{array}$ \\
\hline \multicolumn{3}{|c|}{ Результат - многокритериальная система показателей оченки экономической безопасности } \\
\hline \multicolumn{3}{|c|}{$\begin{array}{l}\text { 2. Ситуационный анализ уровня экономической безопасности субъектов страны на основе многокритериаль- } \\
\text { ной системы показателей }\end{array}$} \\
\hline $\begin{array}{c}\text { Ситуационный анализ и оценка } \\
\text { уровня экономической безопасно- } \\
\text { сти выбранных субъектов (терри- } \\
\text { торий) РФ }\end{array}$ & $\begin{array}{c}\text { Описание уровней экономиче- } \\
\text { ской безопасности, установление } \\
\text { предельных значений показате- } \\
\text { лей по группам, интегрального } \\
\text { показателя } \\
\end{array}$ & $\begin{array}{l}\text { Расчет промежуточных и интеграль- } \\
\text { ных показателей на основе экономи- } \\
\text { ческого моделирования, экспертный } \\
\text { анализ и оценка полученных резуль- } \\
\text { татов } \\
\end{array}$ \\
\hline \multicolumn{3}{|c|}{ Результат - интегральный показатель экономической безопасности субъектов (территорий) РФ } \\
\hline \multicolumn{3}{|c|}{ 3. Классификация регионов по уровню экономической безопасности } \\
\hline $\begin{array}{c}\text { Формирование критериев для трех } \\
\text { уровней экономической безопасно- } \\
\text { сти регионов (территорий) РФ }\end{array}$ & $\begin{array}{l}\text { Распределение регионов по уров- } \\
\text { ням экономической безопасности }\end{array}$ & $\begin{array}{c}\text { Экспертный анализ, ранжирование } \\
\text { по приоритетности }\end{array}$ \\
\hline \multicolumn{3}{|c|}{ Результат - три группь регионов по уровню экономической безопасности } \\
\hline \multicolumn{3}{|c|}{ 4. Применение полученных результатов в территориально-отраслевом планировании } \\
\hline $\begin{array}{c}\text { Проектирование программ терри- } \\
\text { ториально-отраслевого развития, } \\
\text { инструментов и объемов финансо- } \\
\text { во-экономической поддержки }\end{array}$ & $\begin{array}{c}\text { Разработка проектов, бизнес- } \\
\text { планов с показателями эффек- } \\
\text { тивности для бизнеса, региона, } \\
\text { населения }\end{array}$ & Кластерный и сетевой подходы \\
\hline
\end{tabular}

Примечание. Составлено автором.

Внутренние угрозы экономической безопасности регионов

Таблица 2

\begin{tabular}{|l|l|}
\hline \multicolumn{1}{|c|}{ Угроза } & \multicolumn{1}{|c|}{ Проявление действия угрозы } \\
\hline $\begin{array}{l}\text { Истощение природных ресурсов вследствие } \\
\text { преобладания сырьевых форм хозяйствования }\end{array}$ & $\begin{array}{l}\text { Физический и моральный износ производственной базы, некон- } \\
\text { курентоспособность товаров и услуг }\end{array}$ \\
\hline $\begin{array}{l}\text { Низкая степень модернизации производства, } \\
\text { преобладание тяжелого ручного труда }\end{array}$ & $\begin{array}{l}\text { Высокая стоимость готовой продукции, низкая производитель- } \\
\text { ность труда, нерентабельность основной деятельности }\end{array}$ \\
\hline $\begin{array}{l}\text { Низкий спрос на продукцию основных пред- } \\
\text { приятий }\end{array}$ & $\begin{array}{l}\text { Сокращение выручки и прибыли, приостановка производства, } \\
\text { рост безработицы и социальной напряженности, отток населения }\end{array}$ \\
\hline $\begin{array}{l}\text { Низкая прибыль ключевых отраслевых пред- } \\
\text { приятий }\end{array}$ & $\begin{array}{l}\text { Сокращение производства, банкротство, разрушение специали- } \\
\text { зации региона }\end{array}$ \\
\hline $\begin{array}{l}\text { Низкая инвестиционная привлекательность } \\
\text { бизнеса, территории }\end{array}$ & $\begin{array}{l}\text { Отсуствие ресурсов для развития отраслей, локальных } \\
\text { производств, утрата рыночной доли и части потребителей }\end{array}$ \\
\hline $\begin{array}{l}\text { Недостаточный уровень бюджетной } \\
\text { поддержки }\end{array}$ & $\begin{array}{l}\text { Отсутствие возможности реализовать проекты бизнеса, ввести в } \\
\text { действие новые объекты производства, инфраструктуры }\end{array}$ \\
\hline
\end{tabular}

Примечание. Составлено автором. 
Меры обеспечения экономической безопасности

\begin{tabular}{|c|c|c|}
\hline \multirow{2}{*}{ Основные меры } & \multicolumn{2}{|c|}{ Механизмы управления } \\
\hline & Общефедеральный & Региональный \\
\hline \multicolumn{3}{|c|}{ Обеспечивающие меры (анализ, планирование, мониторинг, контроль) } \\
\hline $\begin{array}{l}\text { Ситуационный анализ и оценка } \\
\text { уязвимостей экономической сис- } \\
\text { темы и ее ключевых параметров }\end{array}$ & $\begin{array}{l}\text { Нормативно-правовые, администра- } \\
\text { тивные, экономические, проектно- } \\
\text { целевые }\end{array}$ & $\begin{array}{l}\text { Административные, экономические, } \\
\text { программно-целевые, бизнес-плани- } \\
\text { рование }\end{array}$ \\
\hline $\begin{array}{l}\text { Превентивный, оперативный } \\
\text { мониторинг развития экономи- } \\
\text { ки, достижения качественных и } \\
\text { количественных показателей оп- } \\
\text { тимизации экономической сис- } \\
\text { темы безопасности }\end{array}$ & $\begin{array}{l}\text { Система показателей в аспекте влияния } \\
\text { на макроэкономические параметры }\end{array}$ & $\begin{array}{l}\text { Система показателей в аспекте влия- } \\
\text { ния на рыночные и финансово- } \\
\text { экономические параметры }\end{array}$ \\
\hline \multicolumn{3}{|c|}{ Регулятивно-административные меры (правореализационные, регламентные) } \\
\hline $\begin{array}{l}\text { Совершенствование норматив- } \\
\text { но-правовой базы и институцио- } \\
\text { нальной среды }\end{array}$ & $\begin{array}{l}\text { Уточнение и дополнение системы за- } \\
\text { конодательства на уровне кодифик- } \\
\text { ции и подзаконных актов }\end{array}$ & $\begin{array}{l}\text { Адаптация регионального законода- } \\
\text { тельства субъектов РФ в пределах } \\
\text { своей компетенции }\end{array}$ \\
\hline Антикризисное регулирование & $\begin{array}{l}\text { Компенсаторные механизмы феде- } \\
\text { рального уровня отраслевого и терри- } \\
\text { ториального управления (налогово- } \\
\text { бюджетные льготы, субсидии и т. п.) }\end{array}$ & $\begin{array}{l}\text { Обеспечение оперативного соответ- } \\
\text { ствия мерам поддержки на отрасле- } \\
\text { вом, локальном уровне бизнеса }\end{array}$ \\
\hline \multicolumn{3}{|c|}{ Меры прямого регулирования } \\
\hline антикризисного & $\begin{array}{l}\text { Прямые дотации предприятиям от- } \\
\text { расли, которые влияют на экономику } \\
\text { региона, территории, муниципально- } \\
\text { го образования }\end{array}$ & $\begin{array}{l}\text { Координационная поддержка про- } \\
\text { движения, сбыта продукции, регули- } \\
\text { рования спроса органами исполни- } \\
\text { тельной власти субъекта }\end{array}$ \\
\hline $\begin{array}{l}\text { Государственное регулирование } \\
\text { регионального развития }\end{array}$ & $\begin{array}{l}\text { Целевые проекты социально- } \\
\text { экономического развития регионов с } \\
\text { комплексными мерами }\end{array}$ & $\begin{array}{l}\text { Участие в реализации федеральных } \\
\text { целевых программ, внебюджетное } \\
\text { финансирование }\end{array}$ \\
\hline $\begin{array}{l}\text { Работа с устранение уязвимостей } \\
\text { социально-экономических систем }\end{array}$ & $\begin{array}{l}\text { Совершенствование управления, фи- } \\
\text { нансовой системы, цифровизация и ин- } \\
\text { новация отраслей и предприятий, по- } \\
\text { вышение конкурентоспособности про- } \\
\text { изводителей на международном рынке }\end{array}$ & $\begin{array}{l}\text { Повышение качества управления в } \\
\text { субъекте РФ, выравнивание эконо- } \\
\text { мического развития региона }\end{array}$ \\
\hline
\end{tabular}

Примечание. Составлено автором.

В зависимости от уровня развития экономической специализации и получаемых доходов регионы страны подразделяются на доноров и дотационных, в которых расходы покрываются за счет государственного субсидирования, происходит перераспределение финансовых ресурсов.

Дотации распределяются по регионам страны из бюджета федерального уровня на безвозмездной основе в целях решения социально-экономических и стратегических задач. В России преобладает количество дотационных регионов, поэтому проблема экономической безопасности имеет практическую значимость и связана с национальной безопасностью страны. Статистические данные за 2020 г. свидетельствуют о том, что многие субъекты длительно являются дотационными, не способны обеспечить население всем необходимым в силу сложившихся геополитических и макроэкономических условий (см. рис. 2).

Минимальное количество дотаций, суммой меньше на 55 млрд руб. в сравнении с Республикой Дагестан, выделено Республике Башкортостан. Сегодня только 13 субъектов Российской Федерации обеспечивают поступления в федеральный бюджет, а экономическое положение большинства регионов (72) нуждается в государственной поддержке [Болгучева, 2020].

Субъектов, оказывающих финансовую поддержку, на данный период становится намного меньше, что связано со следующими факторами:

1. Глобальные кризисные явления и макроэкономическая нестабильность влияют на количественное сокращение отраслей и снижение рентабельности производств.

2. Региональные рыночные условия негативно влияют на процессы реализации, про- 


\section{РЕГИОНАЛЬНАЯ ЭКОНОМИКА}

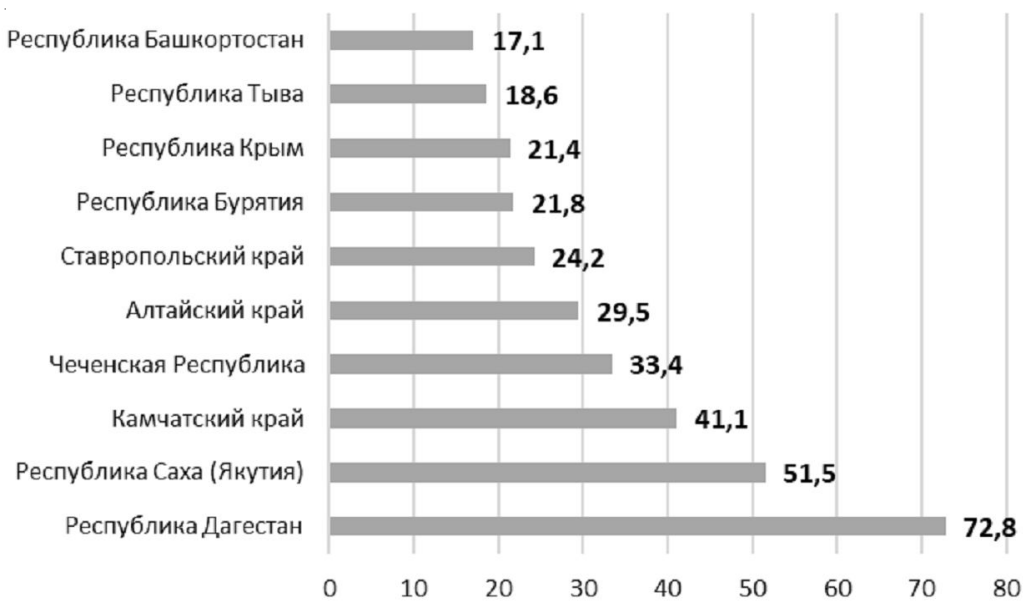

Рис. 2. Дотации регионам России в 2020 г., млрд руб.

Примечание. Составлено автором.

движение продукции, увеличивают транспортно-логистические расходы и затраты на посреднические услуги.

3. Качество и конкурентоспособность отечественной продукции значительно ниже зарубежных аналогичных товаров, она пользуется низким спросом.

4. Санкционная политика в отношении Российской Федерации имеет негативные структурные и финансово-экономические последствия.

Развитие страны в последние годы осуществлялось достаточными темпами, несмотря на то что территориальные различия усиливались. Уровень жизни сильно варьируется в зависимости от региона, значительно различается и социально-экономическое обеспечение. По этой причине депрессивные регионы в Российской Федерации выделяются достаточно ярко. Наблюдается тенденция к увеличению экономического потенциала в определенных областях, он сосредоточен в довольно ограниченных районах страны. 50 \% ВРП создается в Москве, Санкт-Петербурге и Тюмени. Несмотря на то что доля ведущих регионов Российской Федерации в ВРП растет до $60 \%$, в стране остается много депрессивных регионов.

Вопрос, касающийся данной проблемы, регулярно поднимается в политических дискуссиях. Перед лидерами этих областей стоит задача создания благоприятного предпринимательского климата, чтобы депрессивный регион развивался высокими темпами и преодолевал упадок.
Длительное влияние макроэкономических кризисов способствует тому, что регионам страны достаточно трудно адаптироваться к негативным тенденциям и найти способы выхода из сложившейся ситуации. Ряд негативных факторов, которые привели к кризисной ситуации в стране:

1. Сохраняющуюся зависимость от мировых цен на нефть, которые являются низкими.

2. Изменение торгово-экономических соглашений.

3. Влияние пандемии на экономику всех стран, включая Россию.

Низкий уровень развития промышленных секторов обусловлен отсутствием гибкости стратегических программ, неэффективными антикризисными механизмами, в том числе внесением оперативных изменений. Следовательно, положительных тенденций, улучшающих сложившуюся ситуацию можно ожидать только в долгосрочной перспективе. Прогнозы мировых рейтинговых агентств указывают на то, что все страны пройдут через сложный период своего развития [Мудунова, 2017].

Самым крупным получателем дотаций на выравнивание третий год подряд стал Дагестан - из федерального бюджета республика получила более 72 млрд руб., на 6,6 млрд руб. больше, чем в текущем году. Объем дотации рассчитывается в зависимости от уровня финансовой обеспеченности на душу населения, при этом учитываются два показателя - налоговый потенциал террито- 
рии (сколько налогов генерируется, поступает в региональный бюджет) и удорожающий коэффициент, так называемый индекс бюджетных расходов.

Объем субсидий Дагестану объясняется большой многочисленностью населения в республике, так как дотации рассчитываются в среднем на душу населения и умножаются на количество жителей. Еще одна причина - это низкая бюджетная обеспеченность республики. Это связано с низким уровнем налоговых и неналоговых доходов, которые могут поддерживать экономику региона. Около 72 \% доходов от налога на доходы физических лиц формируется в бюджетных секторах экономики государственном управлении, образовании, здравоохранении. Значительная часть заработной платы в этих секторах выплачивается из областного бюджета.

Республика Дагестан в течение последних 20 лет показывала замедление социально-экономических показателей, что со временем привело к сложной социально-экономической ситуации и экономической депрессии. Высокий процент в региональной системе валового продукта в 2019 г. занимала оптовая и розничная торговля $-24,3 \%$, а доля обрабатывающих производств - всего 4,3 \% [Закон Республики Дагестан от 15.07.2011 № 38 ...]. Такой низкий процент обусловлен сложившейся специализацией, Республика Дагестан в большей степени обладает другими ресурсными активами, спроса на продукт обрабатывающей промышленности в регионе нет.

Отсутствие спроса на продукцию обрабатывающей промышленности вызвано следующим:

1. Морально-технологический износ производственных фондов.

2. Низкий уровень инвестиционной привлекательности и финансирования обрабатывающей промышленности, что ограничивает рост производства и потенциал конкурентоспособности.

3. Производственная мощность используется на 20-25 \% [Мисаков и др., 2017].

После 1990-х гг. развитие промышленного сектора резко пошло на спад. В связи с остановкой производства большое количество сотрудников было сокращено, уровень занятости населения снизился, многие предприя- тия были переоборудованы под торговые коммерческие площади.

Кризис не обошел стороной и агропромышленный комплекс, процент сельского хозяйства в региональной системе валового продукта составляет всего $14,2 \%$, даже с учетом того, что аграрный сектор обладает высоким потенциалом. Несмотря на это, основные проблемы связаны в первую очередь с тем, что при большинстве работ используется ручной труд, огромные посевные площади находятся в заброшенном состоянии, не налажен сбыт, инфраструктура находится в упадке. Ряд ограничений обусловлен социальными факторами: отсутствие комплекса производств и предприятий, функционально обеспечивающих нормальную жизнь сельского населения, нехватка квалифицированных кадров, низкая заработная плата, влияющая на высокий уровень миграции населения из сельской местности и так далее [Федотова, 2014].

Для поддержания развития промышленности государству на федеральном и региональном уровне необходимо не только разработать стратегию по привлечению инвестиций в данную область, но и проводить мониторинг качества регионального управления, контролировать инновационные процессы в транспортно-логистическом комплексе, развитие дорожной сети, комплексно решать социальные проблемы, связанные с качеством базовых услуг для населения: образовательные, здравоохранения, жилищно-коммунального хозяйства, транспортные и т. д.

Следует отметить, что остро стоит проблема террористической и коррупционной деятельности, что сказывается на недостатке инвесторов и эффективном развитии экономической деятельности. При решении социальных проблем приоритетной задачей государственной политики должна быть активная борьба с террористической деятельностью и усиление деятельности правоохранительных органов, что является достаточно трудоемким и ответственным процессом [Соболева и др., 2017].

В республике была разработана «Стратегия социально-экономического развития Республики Дагестан до 2025 года», направленная на восстановление социально-экономического положения с целью войти в топ 
лидирующих субъектов РФ по объему ВРП и ИЧР [Закон Республики Дагестан от 15.07.2011 № 38 ...]. К 2025 г. планируется снизить долю субсидий республиканского бюджета с $77 \%$ до $25 \%$.

Основными механизмами реализации стратегии являются федеральные и региональные целевые программы комплексного развития республики, а также меры, направленные на привлечение инвесторов, часть которых уже частично реализована и привела к первым положительным эффектам в экономике. Сегодня в республике уже составлен перечень приоритетных отраслей экономики для реализации 60 инвестиционных проектов, часть из которых находится в разработке, часть реализуется. Инвесторами являются отечественные и зарубежные компании, рассчитывающие на получение государственных гарантий [Баснукаев и др., 2019].

Проведенный анализ показал, что Республика Дагестан может характеризоваться кризисным уровнем экономической безопасности, требующим преобразования ключевых сфер экономики и модернизации производства, влияющего на формирование ВРП субъекта, внедрять механизмы оптимизации использования ресурсного потенциала, реализовывать программы, рассчитанные на привлечение инвестиций.
С учетом проведенного анализа представим процесс выбора эффективных механизмов обеспечения экономической безопасности депрессивных регионов (рис. 3).

Процесс выбора механизмов обеспечения экономической безопасности депрессивных регионов страны должен базироваться на многокритериальной системе оценки уровня социально-экономического состояния объектов исследования и понимании закономерностей формирования экономических связей.

\section{Заключение}

Проблема экономической безопасности регионов является актуальной в условиях макроэкономической нестабильности. Субъекты страны, характеризующиеся экономической депрессией, ограничивают темпы финансово-экономического и рыночного роста, снижают эффективность кооперационных связей и замедляют процессы повышения конкурентоспособности отечественных товаров и услуг. Решение выявленных проблем связано с обеспечением экономической безопасности: устойчивости экономических процессов, способности к воспроизводству и относительной финансово-экономической независимости от федерального бюджета.

Сложность в выборе инструментов и механизмов обеспечения экономической бе-

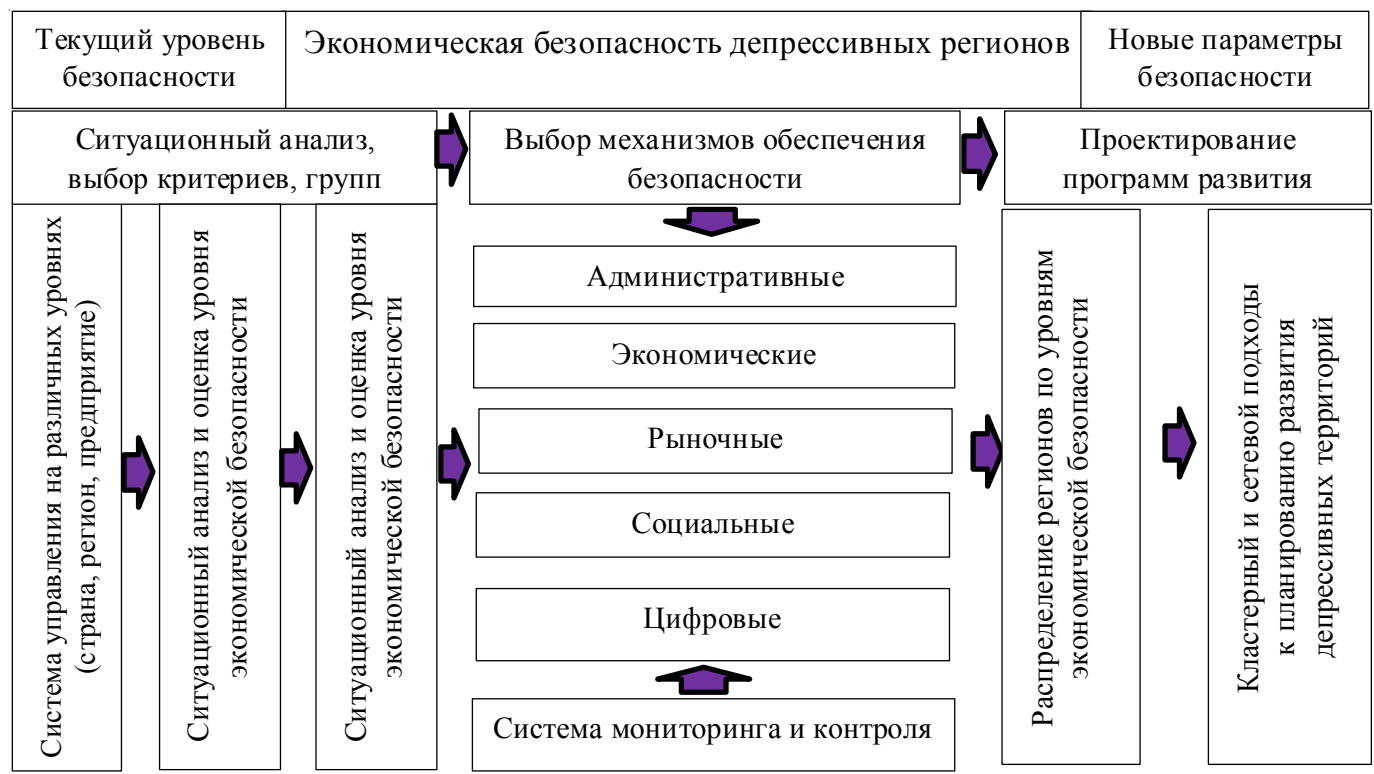

Рис. 3. Процессный подход к определению механизмов обеспечения экономической безопасности депрессивных регионов

Примечание. Составлено автором. 
зопасности депрессивных регионов обусловлена качественными деструктивными изменениями, охватывающими всю социальноэкономическую сферу, что требует последовательных системных мер, реализуемых под контролем государства. Целесообразно применение проектно-целевого управления, задачи и показатели которого будут формироваться на основе многокритериальной системы показателей, позволяющих определить уровень экономической безопасности субъекта РФ, степень государственного вмешательства и объемы финансово-экономической помощи.

\section{СПИСОК ЛИТЕРАТУРЫ}

Акьюлов, Р. И. Проблемы и перспективы мониторинга и оценки социальноэкономической безопасности российских регионов / Р. И. Акьюлов // Вопросы управления. - 2015. - № 4 (16).C. $78-86$.

Баснукаев, М. Ш. Зарубежный опыт налогового регулирования социальноэкономических процессов: возможности использования в России / М. Ш. Баснукаев, И. Я. Эльжуркаев // Финансовые исследования. - 2019. - № 2 (63). C. 99-108.

Болгучева, Р. Б. Некоторые аспекты повышения эффективности налогового стимулирования инвестиционной деятельности в депрессивных республиках СКФО / Р. Б. Болгучева // Естественно-гуманитарные исследования. -2020 . № 27 (1).-C. 39-43.

Долганова, Я. А. Механизм регулирования экономической безопасности регионов (субъектов Российской Федерации) / Я. А. Долганова, М. Н. Руденко // Вестник Прикамского социального института. - 2017. - № 1 (76). С. 97-108.

Ендовицкий, Д. А. Анализ дуализма экономических интересов, в контексте проблемы обеспечения сбалансированного развития региона / Д. А. Ендовицкий, Н. В. Сироткина, А. Ю. Гончаров // Регион: системы, экономика, управление. - 2014. - № 3. - С. 19-26.

Закон Республики Дагестан от 15.07.2011 № 38 «Об утверждении стратегии социально-экономического развития Республики Дагестан до 2025 года». - Доступ из справ.-правовой системы «КонсультантПлюс».

Курляндская, Г. В. Реформирование межбюджетных отношений в субъектах Российской Федерации / Г. В. Курляндская, Е. И. Николаенко // Экономика и жизнь. - 2016. - № 10, 11.
Мисаков, В. С. Инновационная инфраструктура как ресурс достижения сбалансированного развития региона / В. С. Мисаков, В. В. Бут, А. Ю. Аджиева // Экономика и предпринимательство. - 2017. - № 6 (83). - С. 200-203.

Мудунова, А. Ю. Проблемы и перспективы привлечения прямых иностранных инвестиций в экономику Республики Дагестан / А. Ю. Мудунова. - М. : МАКС Пресс, 2017. - 30 с.

Ногмова, Л. А. Формирование экономического потенциала в контексте сбалансированного регионального развития / Л. А. Ногмова, В. С. Мисаков // Известия Кабардино-Балкарского научного центра РАН. - 2016. - № 3 (71). C. 143-148.

Плотников, В. А. Стратегическое управление полюсами инвестиционной привлекательности территорий (по материалам Южного федерального округа) / В. А. Плотников, Г. В. Федотова // Известия ЮЗГУ. Серия: Экономика. Социология. Менеджмент. - 2013. - № 2. - С. 25-31.

Соболева, О. Н. Управление регионом на основе социально-экономического потенциала / О. Н. Соболева, Т. В. Никулина // Экономика и управление: проблемы и решения. - 2017. - С. 39-46.

Федотова, Г. В. Роль институтов развития в реализации государственной инвестиционной программы / Г. В. Федотова // Финансовая аналитика: проблемы и решения. - 2014. - № 5. C. 43-47.

Хадисов, М.-Р. Б. Интегральная оценка уровня экономической безопасности региона при сравнительном анализе / М.-Р. Б. Хадисов // Вестник экономической безопасности. - 2015. T. 4. - C. 71-78.

\section{REFERENCES}

Ak'yulov R.I. Problemy i perspektivy monitoringa i ocenki social'no-ekonomicheskoj bezopasnosti rossijskih regionov [Problems and Prospects of Monitoring and Assessment of Socio-Economic Security of the Russian Regions]. Voprosy upravleniya [Management Issues], 2015, no. 4(16), pp. 78-86.

Basnukaev M.Sh., El'zhurkaev I.Ya. Zarubezhnyj opyt nalogovogo regulirovaniya social'noekonomicheskih processov: vozmozhnosti ispol'zovaniya $v$ Rossii [Foreign Experience of Tax Regulation of Socio-Economic Processes: Opportunities for Use in Russia]. Finansovye issledovaniya [Financial Research], 2019, no. 2(63), pp. 99-108.

Bolgucheva R.B. Nekotorye aspekty povysheniya effektivnosti nalogovogo stimulirovaniya 
investicionnoj deyatel'nosti $\mathrm{v}$ depressivnyh respublikah SKFO [Some Aspects of Improving the Efficiency of Tax Incentives for Investment Activity in the Depressed Republics of the North Caucasus Federal District]. Estestvennogumanitarnye issledovaniya [Natural Humanitarian Studies], 2020, no. 27(1), pp.39-43.

Dolganova Ya.A., Rudenko M.N. Mekhanizm regulirovaniya ekonomicheskoj bezopasnosti regionov (sub"ektov Rossijskoj Federacii) [Mechanism of Regulation of Economic Security of Regions (Territorial Subjects of the Russian Federation)]. Vestnik Prikamskogo social'nogo institute [Bulletin of Prikamsky Social Institute], 2017, no. 1 (76), pp. 97-108.

Endovickij D.A., Sirotkina N.V., Goncharov A.Yu. Analiz dualizma ekonomicheskih interesov, v kontekste problemy obespecheniya sbalansirovannogorazvitiya regiona [The Analysis of Dualism of Economic Interests in the Problem Context Ensuring the Balanced Development of the Region]. Region: sistemy, ekonomika, upravlenie [Region: Systems, Economics, Management], 2014, no. 3, pp. 19-26.

Zakon Respubliki Dagestan ot 15.07.2011 № 38 «Ob utverzhdenii strategii social'noekonomicheskogo razvitiya Respubliki Dagestan do 2025 goda» [Law of the Republic of Dagestan of 15.07.2011 no. 38 "On Approval of the Strategy of socio-economic development of the Republic of Dagestan until 2025"]. Access from Reference Legal System "KonsultantPlyus".

Kurlyandskaya G.V., Nikolaenko E.I. Reformirovanie mezhbyudzhetnyh otnoshenij v sub"ektah Rossijskoj Federacii [Reforming Inter-Budgetary Relations in the Constituent Entities of the Russian Federation]. Ekonomika i zhizn', 2016, no. $10,11$.

Misakov V.S., But V.V., Adzhieva A.Yu. Innovacionnaya infrastruktura kak resurs dostizheniya sbalansirovannogo razvitiya regiona [Innovative Infrastructure as a Resource for Achieving Balanced Regional Development]. Ekonomika $i$ predprinimatel'stvo [Economics and Entrepreneurship], 2017, no. 6(83), pp. 200-203.

Mudunova A.Yu. Problemy $i$ perspektivy privlecheniya pryamyh inostrannyh investicij v ekonomiku Respubliki Dagestan [Problems and Prospects of Attracting Foreign Direct Investment in the Economy of the Republic of Dagestan]. Moscow, MAKS Press Publ., $2017.30 \mathrm{p}$.

Nogmova L.A., Misakov V.S. Formirovanie ekonomicheskogo potenciala $\mathrm{v}$ kontekste sbalansirovannogo regional'nogo razvitiya [Formation of Economic Potential In the Context of the Balanced Regional Development]. Izvestiya Kabardino-Balkarskogo nauchnogo centra RAN [News of the Kabardin-Balkar Scientific Center of RAS], 2016, no. 3 (71), pp. 143-148.

Plotnikov V.A., Fedotova G.V. Strategicheskoe upravlenie polyusami investicionnoj privlekatel'nosti territorij (po materialam Yuzhnogo federal'nogo okruga) [Strategic Management of the Poles of the Investment Attractiveness of Territories (Based on the Southern Federal District)]. Izvestiya YUZGU. Seriya «Ekonomika. Sociologiya. Menedzhment» [Proceedings of South-West State University. Series Economy. Sociology. Management], 2013, no. 2, pp. 25-31.

Soboleva O.N., Nikulina T.V. Upravlenie regionom na osnove social'noekonomicheskogo potenciala [The Management Region Based on the Socioeconomic Potential]. Nauchnoprakticheskij zhurnal Ekonomika $i$ upravlenie: problemy i resheniya [Economics and Management: Problems, Solutions], 2017, pp. 39-46.

Fedotova G.V. Rol' institutov razvitiya v realizacii gosudarstvennoj investicionnoj programmy [The Role of Development Institutions in the Implementation of the State Investment Program]. Finansovaya analitika: problemy $i$ resheniya [Financial Analytics: Science and Experience], 2014, no. 5, pp. 43-47.

Hadisov M.-R.B. Integral'naya ocenka urovnya ekonomicheskoj bezopasnosti regiona pri sravnitel'nom analize [Integral Assessment of the Level of Economic Security of the Region in a Comparative Analysis]. Vestnik ekonomicheskoj bezopasnosti, 2015, no. 4, pp. 71-78. 


\section{Information About the Author}

Matvey S. Oborin, Doctor of Sciences (Economics), Professor, Department of Economic Analysis and Statistics, Perm Institute (Branch) of Russian Economic University named after G.V. Plekhanov, Gagarina Blvd, 57, 614070 Perm, Russian Federation; Professor, Department of World and Regional Economy, Economic Theory, Perm State National Research University, Bukireva St, 15, 614990 Perm, Russian Federation; Professor, Department of Management, Perm State Agro-Technological University named after Academician D.N. Pryanishnikov, Petropavlovskaya St, 23, 614990 Perm, Russian Federation, recreachin@rambler.ru, https://orcid.org/0000-0002-4281-8615

\section{Информация об авторе}

Матвей Сергеевич Оборин, доктор экономических наук, профессор кафедры экономического анализа и статистики, Пермский институт (филиал) Российского экономического университета им. Г.В. Плеханова, бульвар Гагарина, 57, 614070 г. Пермь, Российская Федерация; профессор кафедры мировой и региональной экономики, экономической теории, Пермский государственный национальный исследовательский университет, ул. Букирева, 15, 614990 г. Пермь, Российская Федерация; профессор кафедры менеджмента, Пермский государственный аграрно-технологический университет им. акад. Д.Н. Прянишникова, ул. Петропавловская, 23, 614990 г. Пермь, Российская Федерация, recreachin@rambler.ru, https://orcid.org/0000-0002-4281-8615 